\section{A) Check for updates}

Cite this: Food Funct., 2020, 11, 6186

\title{
Sauce it up: influence of condiment properties on oral processing behavior, bolus formation and sensory perception of solid foods
}

\author{
Arianne van Eck, (D) ${ }^{\text {a,b }}$ Erin Franks, ${ }^{c}$ Christopher J. Vinyard, ${ }^{c}$ \\ Verónica Galindo-Cuspinera, (D) ${ }^{\mathrm{d}}$ Vincenzo Fogliano, (DD ${ }^{\mathrm{a}, \mathrm{b}}$ Markus Stieger ${ }^{\mathrm{a}, \mathrm{b}}$ and \\ Elke Scholten ${ }^{\star a, e}$
}

\begin{abstract}
Condiments are rarely consumed on their own. Although addition of condiments to carrier foods is known to affect oral processing behavior and sensory perception, an understanding of how different condiment properties impact oral processing behavior and sensory perception of solid carrier foods is lacking. This study aimed to understand the role of condiments varying in composition and/or rheological properties in bolus formation facilitation, and how they influence oral processing behavior and sensory perception of solid carrier foods. Two carriers (bread, cooked potato) were combined with mayonnaises differing in fat content and viscosity. Addition of mayonnaises changed bolus properties of solid carrier foods considerably (i.e. decreased bread firmness, increased potato cohesiveness, increased lubrication of both bread and potato bolus) and, consequently, facilitated faster bolus formation. While addition of mayonnaises to bread and potatoes decreased the number of chewing cycles before swallowing, consumers did not change muscle activities or jaw movements per chew. No effect of mayonnaise fat content on oral processing behavior of composite foods was observed. Low viscosity mayonnaise resulted in faster bolus formation and swallowing compared to high viscosity mayonnaise. Low viscosity mayonnaise penetrated faster into bread boli leading to faster softening of bread boli. Also in the case of potato, low viscosity mayonnaise lead to faster bolus formation than for high viscosity mayonnaise. The low viscosity mayonnaise mixed more easily with potato bolus pieces, enhancing adhesion between pieces. Both mayonnaise fat content and viscosity influenced sensory perception of composite foods considerably, especially in terms of fattiness and creaminess. We conclude that oral processing behavior, bolus formation and sensory perception of solid carrier foods can be modified considerably by condiments. While composition and rheological properties of condiments have a large effect on bolus formation and sensory perception of solid carrier foods, these aspects have a limited effect on oral processing behavior of composite foods. Oral processing behavior is dominated by the properties of the solid carrier food. Tailoring condiment-carrier combinations could be an effective strategy to increase healthy eating, alter food intake for populations such as the elderly, and increase food appreciation.
\end{abstract}

Received 30th March 2020, Accepted 17th June 2020 DOI: $10.1039 /$ dOfo00821d rsc.li/food-function

\footnotetext{
${ }^{a}$ TiFN, P.O. Box 557, 6700 AN Wageningen, The Netherlands

${ }^{b}$ Food Quality and Design, Wageningen University, P.O. Box 17, $6700 \mathrm{AA}$ Wageningen, The Netherlands

${ }^{c}$ Department of Anatomy and Neurobiology, Northeast Ohio Medical University, Rootstown, OH 44272, USA

${ }^{d}$ Unilever Innovation Centre Wageningen BV, Bronland 14, 6708 WH Wageningen, The Netherlands

${ }^{e}$ Physics and Physical Chemistry of Foods, Wageningen University, P.O. Box 17, 6700 AA Wageningen, The Netherlands. E-mail: elke.scholten@wur.nl
}

\section{Introduction}

Condiments are popular foods, marked by significant variety in most societies: toppings, seasonings, dressings, sauces, etc. As condiments are consumed multiple times per day, they contribute significantly to our daily food intake. ${ }^{1}$ In the Netherlands, condiments are consumed during the three main meals (breakfast, lunch, dinner) as well as during snacks between meals. ${ }^{2}$ Condiment consumption among the Dutch population increased by $20 \%$ in the period from 2007-2010 to 2012-2016. ${ }^{2}$

Condiments are frequently added to solid carrier foods such as bread, vegetables, potatoes, fish and meat. (Throughout, we refer to the combination of a solid carrier food with a condi- 
ment as a composite food.) Addition of condiments has been suggested to complement or enhance the flavor perception of carrier foods and to increase sensory pleasure. ${ }^{1}$ Sensory complexity increases when two foods differing in mechanical properties and composition are combined into a composite food. ${ }^{3-6}$ Such inhomogeneous composite foods are generally well liked by consumers, presumably because of intra-oral sensory variety perceived throughout consumption. ${ }^{7-9}$ Yet, composite foods receive surprisingly little scientific attention in the field of sensory science and oral processing behavior.

Addition of condiments affects oral processing behavior (i.e. chewing behavior and bolus formation) of solid carrier foods. When condiments were added to bread or crackers, fewer chews, shorter mastication times until swallowing and, consequently, faster eating rates have been observed. ${ }^{10-12}$ Condiments moistened and softened bread boli, leading to faster formation of safe-to-swallow boli. ${ }^{12}$ Condiments also facilitated mastication of raw vegetables. Addition of mayonnaise to raw carrots resulted in fewer chews, shorter mastication times and faster eating rates. ${ }^{13}$ However, faster eating could not be explained by moisture uptake of boli, as carrots are suggested to not absorb moisture like bread and cracker boli. The mechanisms for changes in oral processing behavior caused by addition of condiments to solid carrier foods may therefore differ with composite foods. Little is known about how rheological and physicochemical properties as well as composition of condiments influence oral processing behavior of composite foods.

As condiments are commercially available in a wide range of compositions (e.g. fat content, moisture content) and/or textural properties (e.g. viscosity, friction), we previously studied the effect of type of condiment (solid cheese, cheese spread, mayonnaise) on oral processing behavior of bread and crackers. ${ }^{12}$ Mayonnaise had the largest impact on oral processing behavior of composite foods (i.e. fewest number of chews, shortest mastication time, fastest eating rate), followed by cheese spread and solid cheese which had only limited impact on oral processing behavior. The different effects of the three types of condiments are likely due to their initial food properties, suggesting that condiment consistency affects bolus formation of resulting composite foods. ${ }^{12}$ Differences in bolus formation were also found for bread and crackers as food structure breakdown and bolus formation was affected by the textural properties of such carriers. Addition of condiments to solid carrier foods seems to facilitate bolus formation of com- posite foods in different ways. We hypothesize that adherence of separate solid carrier bolus pieces is enhanced by condiments, which provide lubrication to composite food boli. However, an understanding of how condiment properties and composition contribute to chewing behavior, bolus formation and sensory perception of solid carrier foods is still lacking.

Using a multidisciplinary approach to investigate the link between food structure, chewing behavior and bolus properties is therefore necessary to better understand the transformation of food properties during mastication of composite foods that trigger sensory sensations. ${ }^{14-16}$ This approach has been used previously for a broad range of single foods including model gels, ${ }^{17-21}$ meat $^{22-24}$ bread $^{25-27}$ and biscuits. ${ }^{28}$ As composite foods involve textural changes of two separate foods simultaneously, linking composite food structure to oral processing behavior and sensory perception becomes more challenging.

The aim of this study was to understand the role of condiments, themselves varying in composition or rheological properties, in bolus formation facilitation and how they influence oral processing behavior and sensory perception of solid carrier foods. Condiments (mayonnaises) varying in fat content and viscosity were combined with different carrier foods (bread and cooked potato). These two carrier foods were chosen based on their difference in water absorption capability. We hypothesize that bolus formation of composite foods is affected by condiment viscosity with moisture being absorbed faster by carrier foods when condiment viscosity is low. We hypothesize that high fat of condiments facilitates adherence of composite food boli, and thereby influence bolus properties and sensory perception. By systematically varying the properties of the condiments, this study provides new insights into food oral processing of composite foods, which enables us to gain a better understanding of the structural transitions of foods that contribute to perception. Such knowledge may be useful to increase healthy food intake with high consumer appreciation.

\section{Materials and methods}

\subsection{Samples}

We used mayonnaises varying in fat content and viscosity (Table 1), all were based on the same commercially available mayonnaise recipe (Hellmann's Real, Unilever, The Netherlands). A commercial mayonnaise was used as the full

Table 1 Product properties of mayonnaises varying in fat content, viscosity and type of thickening agent

\begin{tabular}{lllll}
\hline & FF-HV & LF-HV-starch & LF-HV-xanthan & LF-LV \\
\hline Fat content & Full fat (FF) & Low fat (LF) & Low fat (LF) & Low fat (LF) \\
$(\% \mathrm{w} / \mathrm{w})$ & 73 & 20 & 20 & 20 \\
Viscosity & High viscosity (HV) & High viscosity (HV) & High viscosity (HV) & Low viscosity (LV) \\
At $1 \mathrm{~s}^{-1}$ (Pa s) & $60 \pm 12$ & $92 \pm 22$ & $149 \pm 16$ & $2 \pm 0.2$ \\
At $10 \mathrm{~s}^{-1}$ (Pa s) & $9 \pm 2$ & $13 \pm 3$ & $16 \pm 1$ & $0.4 \pm 0.04$ \\
At $100 \mathrm{~s}^{-1}$ (Pa s) & $1.3 \pm 0.3$ & $1.9 \pm 0.4$ & Xanthan & $0.1 \pm 0.01$ \\
Thickening agent & - & Starch & 3 & - \\
$(\% \mathrm{w} / \mathrm{w})$ & - & 5 & & -
\end{tabular}


fat/high viscosity version (FF-HV; Hellmann's Real, Unilever, The Netherlands). The low-fat/high viscosity (LF-HV) and lowfat/low viscosity (LF-LV) mayonnaises were prepared for this study at a pilot plant and are not commercially available. Two types of LF-HV mayonnaise were prepared, in which either starch or xanthan was used as a thickening agent (LF-HVstarch, LF-HV-xanthan). As starch can be degraded by salivary enzymes, the viscosity of mayonnaises with starch was assumed to decrease faster during oral processing than the mayonnaise thickened with xanthan.

Mayonnaises were combined with solid carrier foods to form composite foods. Two commercial carrier foods were used: bread (whole grain casino bread, Albert Heijn, The Netherlands) and purple potatoes (Solanum tuberosum, Albert Heijn, The Netherlands). Bread and potatoes were selected based on their difference in water absorption capability. Bread is speculated to absorb moisture during oral processing, whereas boiled potatoes are assumed to absorb less moisture. Dark bread and purple potatoes were chosen to increase color contrast between condiment and carrier foods in expectorated boli to facilitate qualitative visualization of mixing behavior of condiments with carriers (see section 2.2.5.1). Fresh bread without crust was cut in squares of $35 \times 35 \times 8 \mathrm{~mm}$ of approximately $3.5 \mathrm{~g}$ (moisture content: $44 \pm 3 \mathrm{wt} \%$ ). Potatoes were peeled, cut in small beams of $\sim 70 \times 12.5 \times 12.5 \mathrm{~mm}$ of approximately $6.5 \mathrm{~g}$, vacuum packed into heat-resistant plastic bags, and cooked sous-vide at $90{ }^{\circ} \mathrm{C}$ for $15 \mathrm{~min}$ (moisture content: 88 $\pm 1 \mathrm{wt} \%)$. After cooking, all bags were cooled in ice water for $15 \mathrm{~min}$ and stored in the refrigerator $\left(4^{\circ} \mathrm{C}\right)$ for up to six days.

For carrier-mayonnaise combinations, mayonnaise was spread on top of bread (simplified model for bread with spread), and potatoes were completely covered by mayonnaise (simplified model for potato salad with mayonnaise dressing). Approximately $3.5 \mathrm{~g}$ of mayonnaise was added to the carriers leading to a 1:1 weight ratio for bread-mayonnaise combinations and a $2: 1$ weight ratio for potato-mayonnaise combinations. This was based on the weight ratios of bread with spreads and vegetables with condiments of previous studies and is representative for weight ratios during normal consumption behavior. ${ }^{12,13}$ Carrier-mayonnaise combinations were prepared just before serving to minimize moisture transfer of the mayonnaises into the carriers before consumption. In addition, carriers were assessed alone as a reference.

\subsection{Oral breakdown of composite foods}

2.2.1. Subjects. A group of 16 Caucasian, European females $(22.9 \pm 2.5$ years, mean $\pm \mathrm{SD})$ participated in the study. All subjects were consumers of bread, potato and mayonnaise on a regular basis, had good dental health (self-reported), and were non-smokers (self-reported). A homogeneous group of subjects $(n=16)$ was selected to alleviate inter-individual subject variation. Selection was based on age, gender, mechanically stimulated saliva flow rate $\left(3.2 \pm 0.5 \mathrm{~g} \mathrm{~min} \mathrm{~m}^{-1}\right.$, mean \pm SD) and natural eating time from a selection of samples (13 $\pm 3 \mathrm{~s}$ for both mayonnaise-bread combinations and mayonnaise-potato combinations, mean $\pm \mathrm{SD}$ ), which were assessed during a one hour long screening session ( $n=$ 33 recruited subjects). Subjects with low/high saliva flow rates (top and bottom 10\%) and fast/slow mastication times (top and bottom $10 \%$ ) were excluded from participation. A homogeneous group of subjects was selected to minimize inter-individual subject variation, since the focus of the study was to understand the role of condiments varying in composition or rheological properties in food oral processing behavior and sensory perception of solid carrier foods. All subjects gave written informed consent, completed the study and received financial compensation for participation.

2.2.2. Experimental approach. Subjects participated in 9 sessions over three months, each lasting at most 45 minutes. In the first two sessions, natural oral processing behavior was recorded by video to calculate bolus expectoration time points. The next five sessions were used for bolus collection to characterize various bolus properties (section 2.2.5). In the last two sessions, we quantified oral processing during mastication using electromyography (EMG) and jaw tracking (JT) (section 2.2.4).

For all sessions, samples were presented with three-digit codes in a random order following a completely randomized design. All samples were served on a spoon. Between each sample, subjects cleansed their palate with cold water and tea (Jasmine green tea, Twinings, UK) for at least 1 minute. They used tongue scrapers to aid the removal of oil from their tongue.

2.2.3. Characterization of oral processing behavior using electromyography and jaw tracking. Muscle activity and threedimensional jaw movements were recorded simultaneously. Electromyographic (EMG) activity was recorded bilaterally from the superficial masseter, anterior temporalis, and anterior digastric muscles at $1000 \mathrm{~Hz}$ using surface electrodes (BioFlex, BioResearch Assoc. Inc., Milwaukee, WI). Muscle position was located by palpation while participants clenched their teeth and electrodes were adhered to the skin overlying the muscles. Participants held a ground electrode to minimize electrical background noise. Lead wires were connected to the BioEMG III amplifier, which passed amplified EMG signals to a recording computer. Mandibular movements were recorded using a jaw tracking device (JT-3D, BioResearch Assoc., Inc.), which records incisor-point movements in three-dimensions. A small magnet was attached to the lower central incisors with a dental-grade adhesive (Stomahesive, ConvaTec, Princeton, NJ). Movement of the magnet was tracked by an array of sensors securely fit as a unit on the subject's head to record vertical, anteroposterior, and lateral components of the jaw relative to the cranium during mastication. During data collection, jaw kinematics (magnet position) and EMG signals were electronically recorded synchronously using BioPAK software (v6.0, BioResearch Assoc., Inc.).

Raw EMG data were band-pass filtered at 100-3000 Hz. To provide a single waveform for analyses, raw EMG data were transformed by calculating the root mean square (rms) of each digitized raw EMG signal at $2 \mathrm{~ms}$ intervals over a $42 \mathrm{~ms}$ time constant using LabView Graphical Programming System 
(National Instruments Corporation, Austin, TX). ${ }^{29,30}$ A chewing sequence was produced for each sample from the simultaneous recordings of jaw movements and rms-EMG activity. As with the video recordings, total mastication time (s), number of chews and chewing frequency (chews per s) were determined. More detailed parameters including chewing cycle duration (opening, closing, power stroke), chewing velocities (during opening, closing), chewing movements (vertical, anterior posterior and medial lateral direction) and muscle activities (temporalis, masseter and digastric; per chew and during the sequence) were also collected to comprehensively analyze jaw-muscle activity and jaw-kinematic patterns.

2.2.4. Characterization of bolus properties throughout consumption. Several bolus properties (moisture content, saliva content, fat content, mechanical properties, friction coefficient) were characterized at 33, 66 and/or $100 \%$ of the chewing sequence. These time points were defined for each sample by averaging the total mastication time of all subjects and all replicates extracted from the video recordings, following the method described by van Eck et al. (2019). ${ }^{12}$ Subjects attended five bolus collection sessions over a time period of one month. These sessions were divided in three parts: (1) boli were collected at 33, 66 and 100\% of total mastication for image acquisition, followed by dry matter analysis and subsequent fat content analysis, (2) boli were collected at 33, 66 and $100 \%$ of total mastication for the analysis of the mechanical properties (30 samples were served over two sessions), and (3) boli were collected at $100 \%$ of total mastication time for tribological analyses (10 samples were served over 1 session). Serving order was randomized for sample and time point. To collect the boli, subjects were instructed to chew a sample for a given number of seconds using a stopwatch, to expectorate the bolus into a Petri dish, and to cover the Petri dish with a lid. All boli were analyzed immediately after expectoration to prevent moisture evaporation from the samples.

2.2.4.1. Bolus images. Pictures of expectorated boli were taken for all samples $(n=10)$, all time points $(n=3)$ and all subjects $(n=16)$ using an image acquisition system (IRIS VA 400, AlphaMOS, France). Pictures were used to qualitatively illustrate differences between food boli, time points and subjects. Pictures were not analyzed for quantitative data.

2.2.4.2. Moisture and saliva content. Moisture and saliva content of boli were determined by dry matter content analysis for all samples and time points. Boli were placed on aluminum dishes, weighed, dried for $16-18 \mathrm{~h}$ at $105^{\circ} \mathrm{C}$ in an atmospheric oven (Venti-line, VWR®), and weighed again after drying. Bolus moisture content (MC) on a wet weight basis was calculated using $\mathrm{MC}=\left(m_{0}-m_{1}\right) / m_{0} \times 100 \%$, where $m_{0}$ is the weight before drying and $m_{1}$ is the weight after drying. Bolus moisture content on a dry weight basis was calculated using $\mathrm{MCdb}=$ $\left(m_{0}-m_{1}\right) / m_{1}$, which was subsequently used to calculate the saliva content (SC) by subtracting the moisture content of the product from the moisture content of the bolus (MCdb).

2.2.4.3. Fat content. Total fat content of all carrier-mayonnaise boli expectorated at $100 \%$ of mastication time were determined using Soxhlet extraction with petroleum ether.
Total fat content determination was completed immediately after dry matter analysis. Total fat content on a dry weight basis (FCdb) was calculated using FCdb $=f_{1} / \mathrm{db}_{0}$ where $f_{1}$ is the weight of fat after evaporation and $\mathrm{db}_{0}$ is the weight of the dried bolus before extraction. Plain carrier boli were not analyzed since fat is absent in these products.

2.2.4.4. Mechanical properties. Mechanical properties of boli presented in Petri dishes were determined by a two cycle puncture test for all samples and time points, following van Eck et al. (2019). ${ }^{12}$ A Texture Analyzer (TA.XT Plus) equipped with a $500 \mathrm{~g}$ load cell and a cylindrical probe with a diameter of $4 \mathrm{~mm}$ was used. Puncture tests were performed up to a strain of $50 \%$ of the initial bolus height (typically $10 \mathrm{~mm}$ ) at three different locations of the expectorated bolus, which were used as replicate measurements. A constant speed of $5 \mathrm{~mm} \mathrm{~s}^{-1}$ was used. After the first puncture, the probe was retracted from the samples and a resting time of $5 \mathrm{~s}$ was used before the second puncture was applied. Bolus firmness, adhesiveness and cohesiveness were determined from the force-strain curves as described by Devezeaux de Lavergne et al. (2015). ${ }^{19}$ Firmness was defined as the maximum peak force during the first puncture cycle. Adhesiveness (i.e. food sticking to probe) was defined as the area under the negative force-strain curve measured during the retraction of the probe from the samples in the first cycle. Cohesiveness (i.e. food sticking together) was defined as the ratio between the area under the positive forcestrain curve obtained during the second and first puncture cycle.

2.2.4.5. Friction coefficients of boli. Coefficients of friction of all boli expectorated at $100 \%$ of mastication time were determined using a tribometer (TriboLab, Bruker, Karlsruhe, Germany), following a procedure described by Fuhrmann et al. (2019). ${ }^{31}$ Boli expectorated at 33 and $66 \%$ of mastication time were not analyzed since these samples were too inhomogeneous. Each bolus was split in two samples, after which each half of the bolus was placed on the substrate and gently leveled with a spoon. The substrate was a roughened PDMS mat $(60 \times 40 \mathrm{~mm})$ to mimic the in-mouth surface. The container was moved in an oscillating fashion over a distance of $6 \mathrm{~mm}$ with an increasing speed from 0 to $12 \mathrm{~mm} \mathrm{~s}^{-1}$. The upper surface was a cylindrical probe with a diameter of $30 \mathrm{~mm}$ made from roughened PDMS $\left(706 \mathrm{~mm}^{2}\right)$. The normal force applied during the measurement was $0.5 \mathrm{~N}$. The PDMS substrate and PDMS probe were cleaned with ethanol and water prior to each measurement. Coefficient of friction (COF) was calculated using the advanced oscillating COF algorithm provided with the UMT viewer software.

\subsection{Sensory descriptive analysis}

Quantitative descriptive sensory analysis was performed using Unilever Foods' absolute scaling method (UFASM) with a trained panel consisting of Dutch women $(n=12)$ with an average age of $58 \pm 8$ years (mean $\pm \mathrm{SD}$ ). All panelists were already familiar with the sensory attribute lexicon and with a large variety of mayonnaises, as they have been trained and 
performed mayonnaise evaluation sessions for years (at least twice per week).

Two familiarization sessions of 3 hours took place to acquaint the panel with the different carrier-mayonnaise combinations, as although they had years of experience with the evaluation of plain mayonnaises, they did not have experience with composite foods. The first session was used to discuss the attributes with definitions (Table 2). Attributes were based upon past lexicons developed for mayonnaise evaluation, and attributes applicable to carrier-mayonnaise combinations were determined during a panel discussion. The second training session was used to set the attribute order, after which the panel practiced with the FF-HV, LF-HV-xanthan and LF-LV mayonnaises without and with carriers. The panelists used a 15-step categorical scale ranging from 0 to 15, where 0 represented not at all and 15 represented extremely high intensity.

The panel attended two evaluation sessions of 2.5 hours each ( 1 hour - 30 min break - 1 hour) over a period of two weeks. The sessions were organized by sample type: bread without/with mayonnaise was evaluated in the first session and potato without/with mayonnaise was evaluated in the second session. At the start of each session, the panel evaluated one warm-up sample (FF-HV) to avoid first-order-effects. All samples were coded with 3-digit random codes, evaluated in duplicate and presented in a random order following a balanced design. Between each sample, subjects cleansed their palate with cold water, tea (jasmine green tea, Twinings, UK) and crackers (Barber cream crackers, Burton's Biscuit Co., UK) for at least 2-3 minutes.

\subsection{Statistical data analyses}

Data were collected for carriers (bread, potato) with mayonnaises varying in fat content (high/low), viscosity (high/low) and thickening agent (starch/xanthan). As a reference, carriers without mayonnaises (single bread, single potato) were assessed to show the impact of the different mayonnaises on chewing behavior, bolus formation and sensory perception of carriers.

To investigate the effect of mayonnaise properties on chewing behavior, bolus formation and sensory perception of carrier-mayonnaise combinations, linear mixed models were performed using Lmer package in R. ${ }^{32}$ Mayonnaise, carrier and mayonnaise: carrier interaction were set as fixed effects and subject, serving order, session (if applicable) and replicate (if applicable) were set as random effects. Data on single carriers (i.e. without mayonnaise) were used illustratively, and were not included in the linear mixed models. Multiple factor analysis (MFA) was performed to compare the different data sets (video recordings, EMG and jaw tracking, bolus properties at moment of swallowing and static sensory characteristics) simultaneously, using FactoMineR package. ${ }^{33}$ For this analysis, only those parameters with a significant mayonnaise effect during mixed models were considered. Furthermore, Pearson's product-moment correlations $(r)$ were used to determine relationships between averaged coefficient of friction of boli and sensory perception (smoothness, dry and rough afterfeel). $\mathrm{R}$ language (RStudio, version 1.0.143) was used to perform all statistical tests. Significance level of $p<0.05$ was chosen.

\section{Results and discussion}

The aim of the study was to understand the role of condiments varying in composition or rheological properties in bolus formation facilitation, and how they influence oral processing be-

Table 2 Sensory attributes and definitions used during the quantitative descriptive sensory analysis using Unilever Foods' absolute scaling method (UFASM) with a trained panel $(n=12)$

\begin{tabular}{lll}
\hline Modality & Attribute & Definition \\
\hline Odor & Overall odor intensity & The intensity of the odor totality \\
Taste & Overall taste intensity & The intensity of the taste totality \\
Mouthfeel & Dry and rough feeling on the tongue or in the mouth & Degree of firmness (the force needed to press the sample between the tong and the palate) \\
& Firm & Degree of stickiness \\
& Sticky & Degree of small soft gel particles or lumps \\
& Gummy & Degree of creaminess like whipped cream \\
& Fatty & Degree of fatty feeling \\
& Velvet & Degree of creamy feeling such as Calve full fat mayo (soft and velvet) \\
& Smooth & Degree of slippery feeling \\
& Salivating & Degree of salivation or mouthwatering due to secretion of saliva \\
& Absorbing & Degree of mayonnaise absorbance in the bread/the potato \\
& Chewing effort & Degree of effort to chew the sample/form a bolus \\
& Homogeneous & Degree of mixing of mayonnaise with the bread/the potato (in the mouth) \\
& Bread fibers & \\
& Potato particles & \\
& Residue & Degree of a fiber feeling, due to the presence of bread in the mouth \\
Fatty film layer & Degree of a particles feeling, due to the presence of potato pieces in the mouth \\
Dry, rough & A substance remains in the mouth (in the molars) \\
Cleaning effort & A fatty film, coating remains in the mouth \\
& Dry and rough feeling remains on the tongue or in the mouth \\
& Degree of effort to clean the mouth after eating the sample
\end{tabular}

${ }^{a}$ The sensory attribute bread fibers was assessed for bread samples only. The sensory attribute potato particles was assessed for potato samples only. 


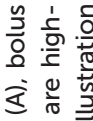

흘

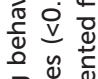

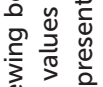

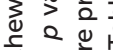

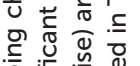

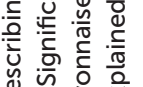

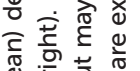

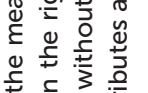

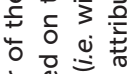

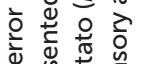

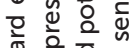

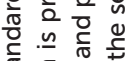

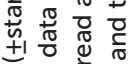

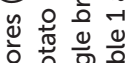

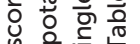

究造

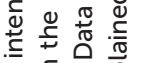

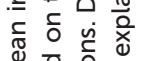

है 월 윻

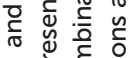

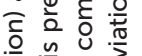

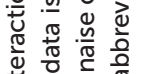

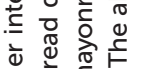

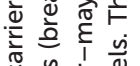

峁

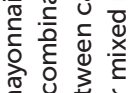

है

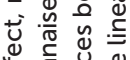

売

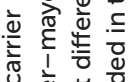

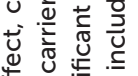

击

虫

旅

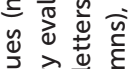

ग 월

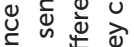

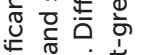

흔무응 흘

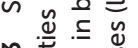

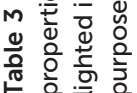

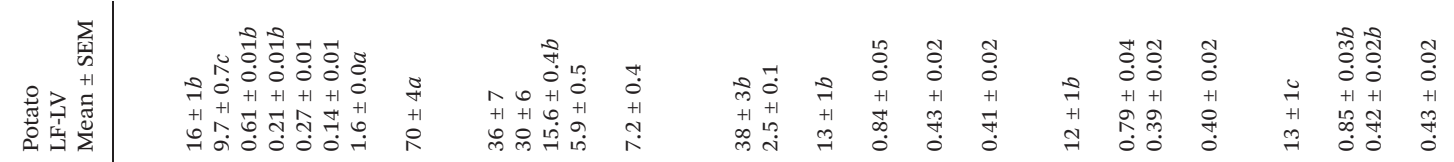

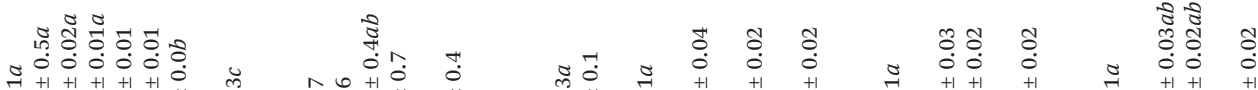

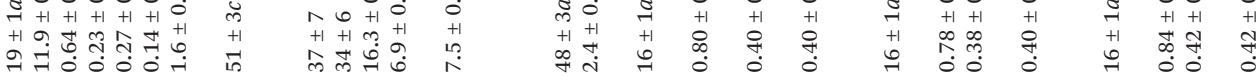

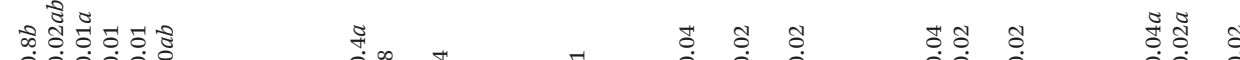

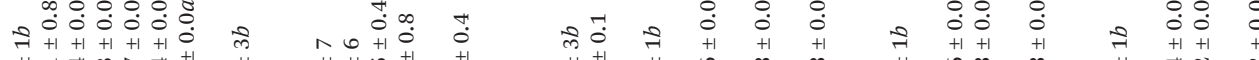

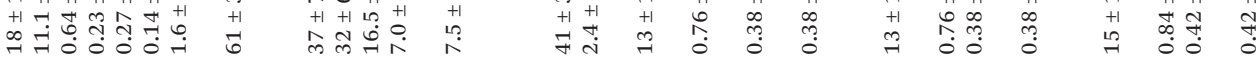

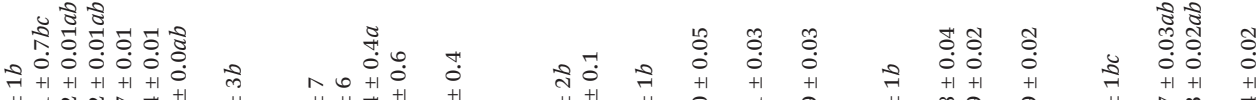

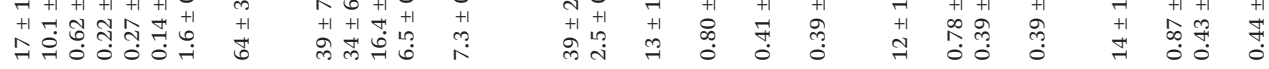

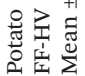

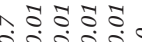

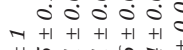

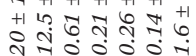

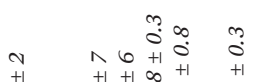
ह

苞寻密

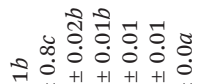

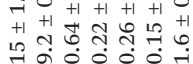

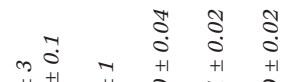

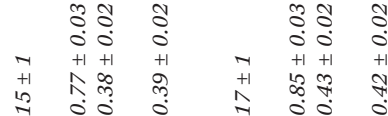

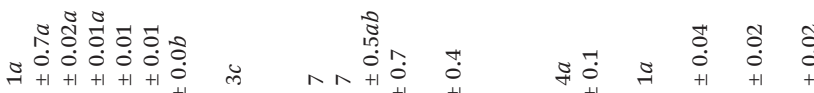

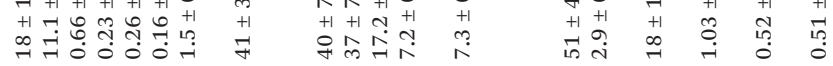

$\begin{array}{rrrrr}0 & 0 \\ 0 & 0 & 0 & 0 & 0 \\ 0 & 0 & 0 & 0 \\ 0 & 0 & 0\end{array}$

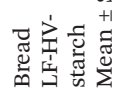

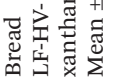

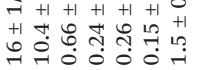

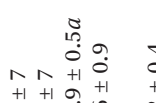

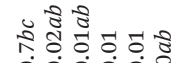

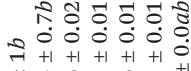

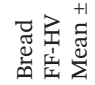

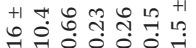

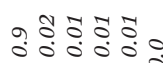

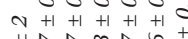

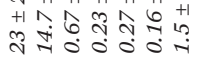

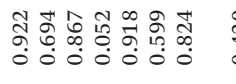

\begin{tabular}{l|l} 
& \\
0 & 2 \\
$\Sigma$ & \\
$\sum$ & 1
\end{tabular}

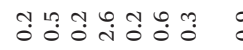

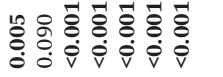

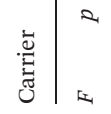

ㄲำ

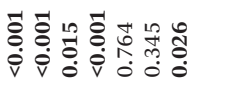

m

尊

s.

0
$\infty$
$\infty$

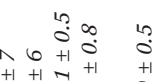

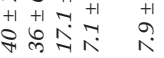

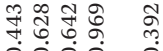

007

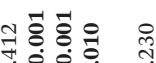

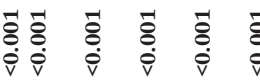

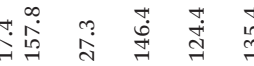

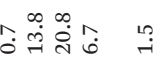

苛薄

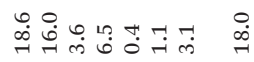

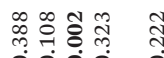

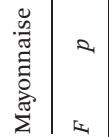

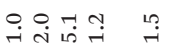

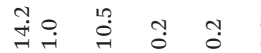

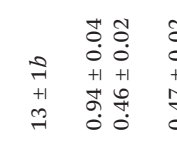

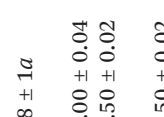

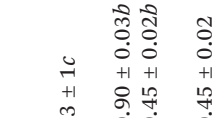

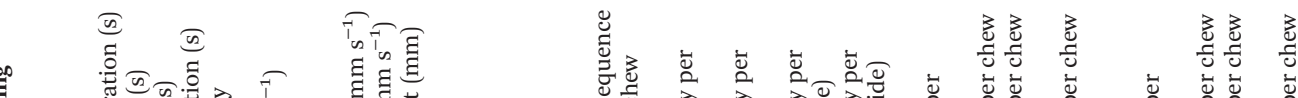

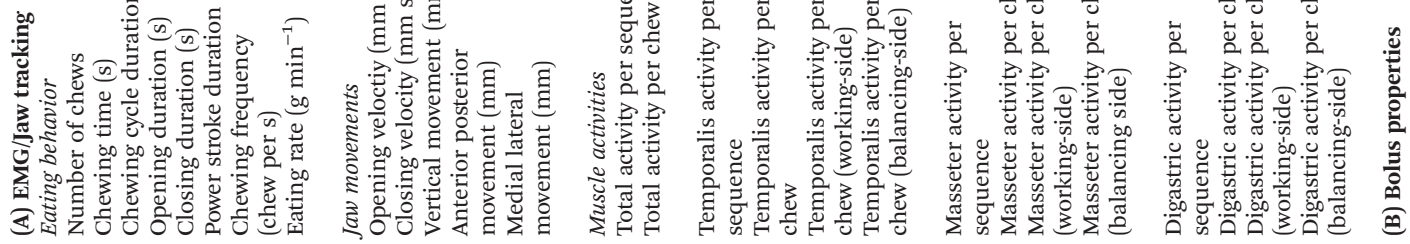




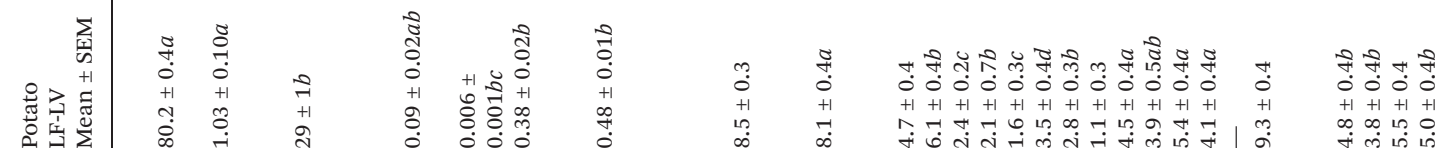

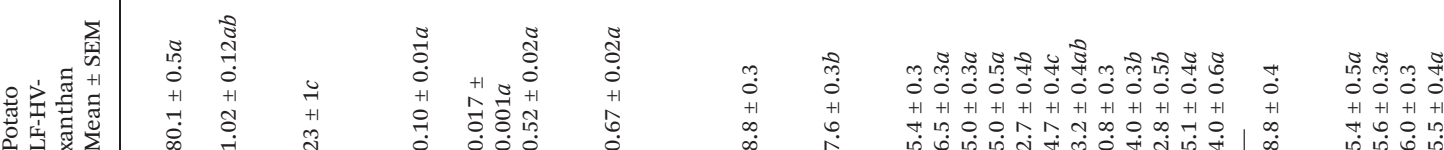

总

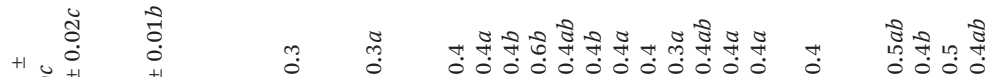

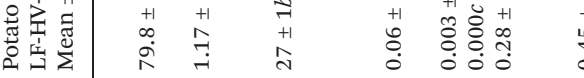

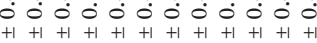

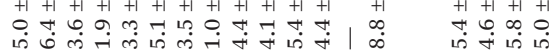

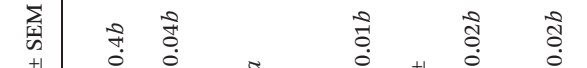

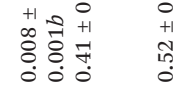

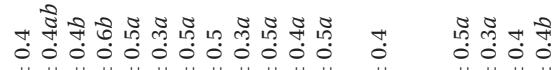

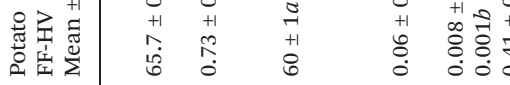

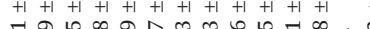

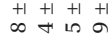

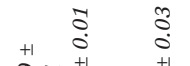

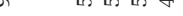

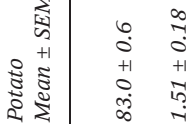

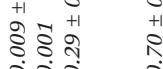

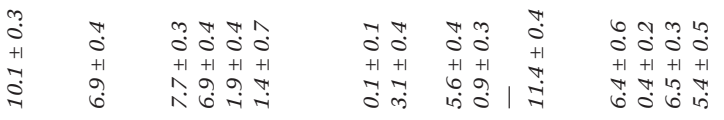

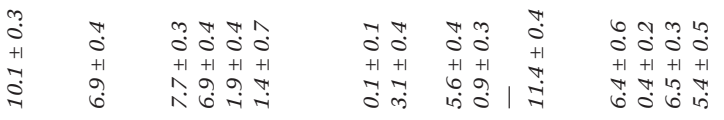

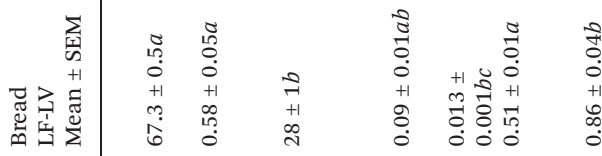

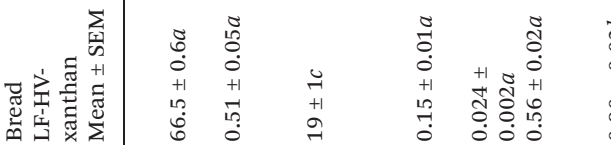

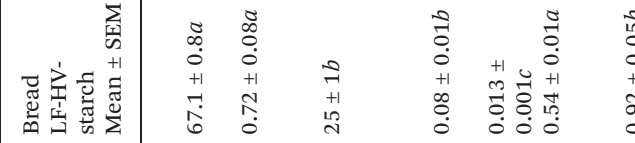

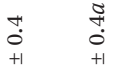

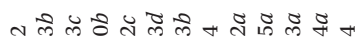

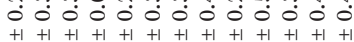

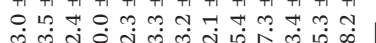

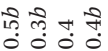

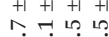

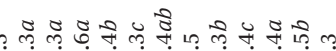

0.0ं0.0 0.0.0.0

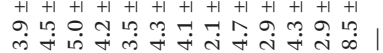

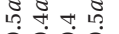

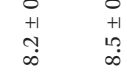

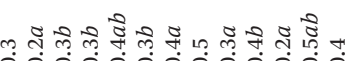

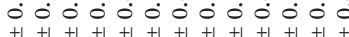

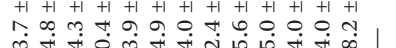

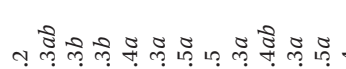

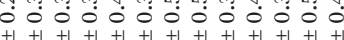

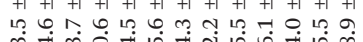

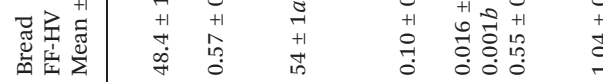

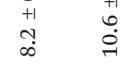

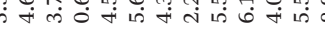

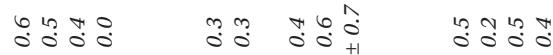

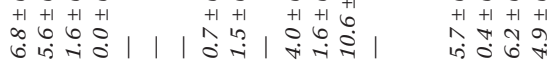

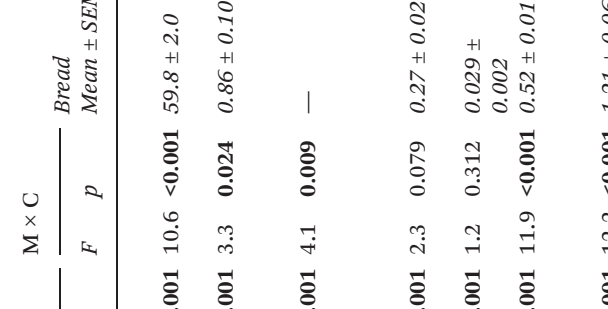

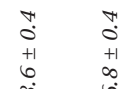

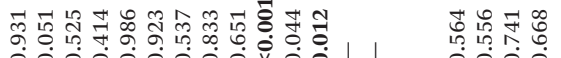

000000000700110000

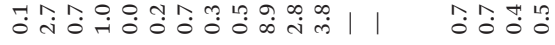

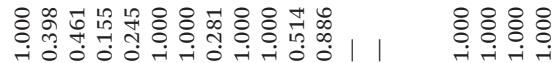

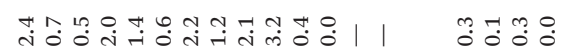

莺

$v$

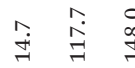

高 $\overline{\dot{0}}$

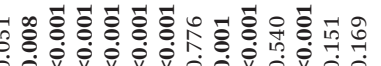

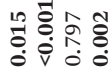

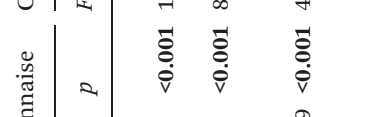

$\stackrel{\circ}{\circ} \stackrel{\infty}{\circ} \stackrel{\circ}{\circ}$

in

\begin{tabular}{lll}
\multirow{2}{*}{} & $\overline{8}$ \\
0 & $\stackrel{0}{0}$ \\
0 & 0
\end{tabular}

monthes

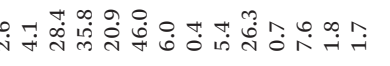

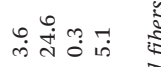<smiles>C1CCCC1</smiles>

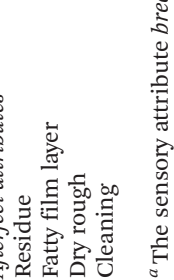


havior and sensory perception of composite foods. The results of all measurements (bolus formation, oral processing behavior, sensory perception by a trained panel) are summarized in Table 3 together with the results of the statistical data analysis. To be concise, results of different measurements are linked and discussed together in the following sections and are not always discussed individually.

To gain further insights into bolus formation during oral processing and the accompanying sensory perception, a full fat mayonnaise with high viscosity (FF-HV), a low-fat mayonnaise with low viscosity (LF-LV), and two low-fat/high viscosity mayonnaises (LF-HV) were assessed. For the LF-HV mayonnaises, a thickening agent was added to compensate for the decrease in viscosity with reduction in fat content. Two different thickeners were investigated, starch (which is frequently used in the preparation of low-fat mayonnaises; LF-HV-starch) and xanthan (LF-HV-xanthan). These thickeners were chosen based on their sensitivity of amylase present in saliva. Starch is broken down by $\alpha$-amylase, which was expected to decrease the viscosity throughout mastication. As a comparison, we also used xanthan, which is not broken down by $\alpha$-amylase, and therefore the viscosity was expected to remain the same through consumption. Although the rheolo- gical properties of the two mayonnaises were similar (Table 1), perception of the two mayonnaises was quite different according to the trained sensory panel. The structure of LF-HVxanthan mayonnaise was perceived as gummy (gummy mouthfeel was $7.5 \pm 0.7$ for LF-HV-xanthan compared to $0.2 \pm 0.1,0.5$ \pm 0.3 and $0.0 \pm 0.0$ for FF-HV, LF-HV-starch and LF-LV, respectively). Gummy perception dominated the eating experience and this was strongly disliked by the subjects, as free comments of both the consumer and trained panel indicated. In contrast to xanthan, starch is used commonly as a thickening agent in commercially available low-fat mayonnaises. As a consequence, the following section focuses on comparisons between HF-HV, LF-LV and LF-HV-starch rather than with LF-HV-xanthan.

\subsection{Oral processing behavior of carrier foods with added condiments}

3.1.1. Oral processing behavior of carrier foods with and without condiments. Table 3 provides a general overview of the results. The addition of mayonnaises decreased the number of chewing cycles and increased eating rate significantly for both solid carrier foods (Fig. 1). On average, the number of chews decreased from $23 \pm 2$ to $16 \pm 2$ for bread
(A)

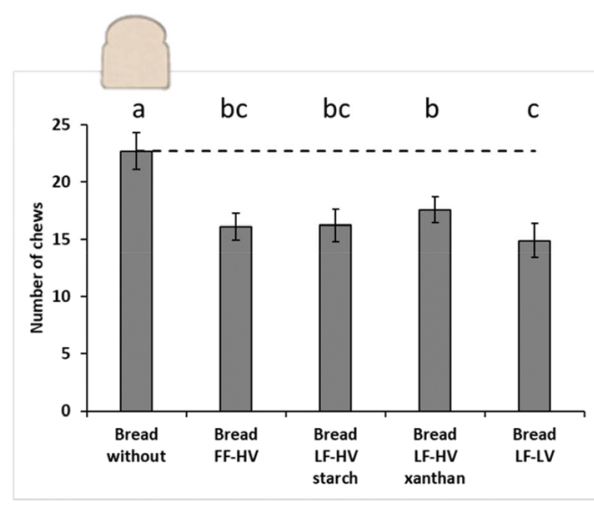

(C)

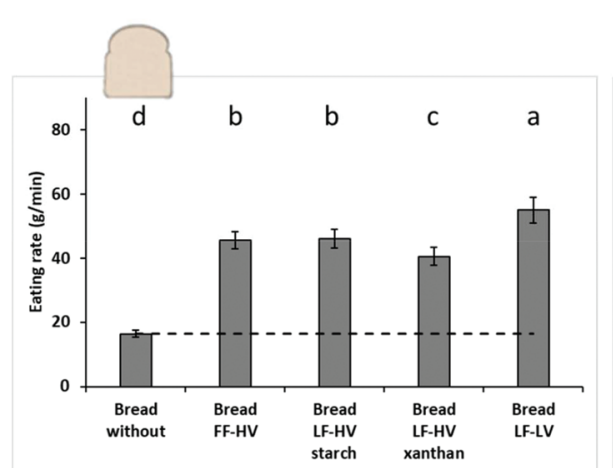

(B)

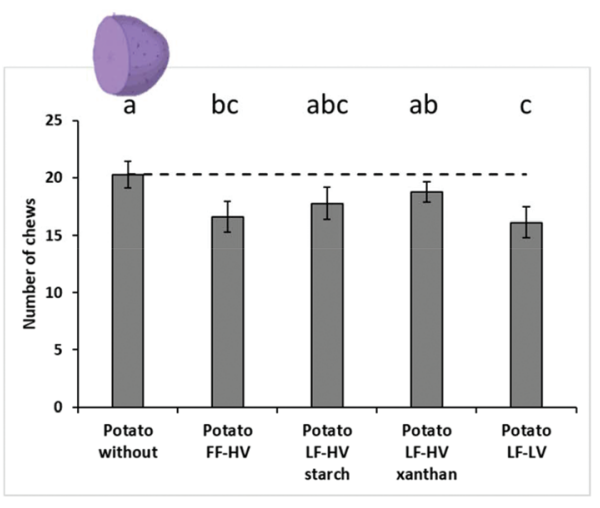

(D)

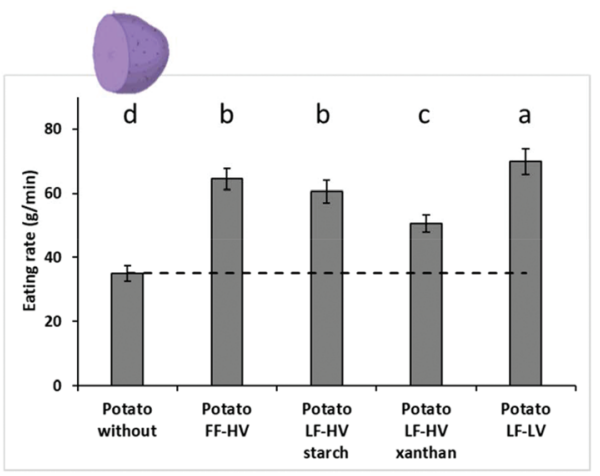

Fig. 1 Number of chews required until swallowing and eating rate $\left(\mathrm{g} \mathrm{min}^{-1}\right)$ for bread $(\mathrm{A}, \mathrm{C})$ and cooked potato (B, D) without and with different mayonnaises, determined using electromyography. Dashed lines represent the averaged value of single carriers. Error bars represent standard error of the mean. Different lower case letters indicate significant differences between means $(p<0.05)$. The abbreviations are explained in Table 1 . 
$(-30 \%)$ (Fig. 1A) and from $20 \pm 1$ to $17 \pm 1$ for potato $(-15 \%)$ (Fig. 1B). However, addition of mayonnaise did not affect muscle activities and jaw movements per chew for bread and potato. This is noteworthy, as addition of mayonnaise softened the bread and potato boli. This can be seen in the mechanical properties of the products over consumption time, as given in Fig. 2. Here, we use the peak force of the expectorated boli as a representative measure of firmness. As firmness perception decreased (from $5.6 \pm 0.5$ to $4.4 \pm 0.3$ for bread, and from $6.9 \pm$ 0.4 to $6.2 \pm 0.4$ for potato), it might be expected that chewing would take less effort when mayonnaises are added to solid carrier foods, but this was not reflected in muscle activities and jaw movements per chew. Lower chewing effort was reflected in a decreased total chewing time until swallowing, as subjects adjusted their oral processing behavior when mayonnaises were added by decreasing number of chews while maintaining muscle activities and jaw movements per chew. The eating process was thus faster. In this instance, chewing force and jaw movements during individual cycles are largely independent of condiments meaning that changes in condiment properties do not markedly alter oral physiology during individual chewing cycles.
3.1.2. Bread versus potato: the effect of condiment addition on oral processing behavior. Clear differences in oral processing behavior were observed for bread and cooked potato (Table 3A). Plain wholegrain bread was processed using more chews per chewing sequence (23 \pm 2 vs. $20 \pm 1$ ), higher muscle activities per chew $(3.0 \pm 1.0$ vs. $2.4 \pm 0.1)$ and larger jaw movements per chew $(17.1 \pm 0.5$ vs. $15.8 \pm 0.3 \mathrm{~mm}$ in vertical direction) than cooked potato, although bite size was smaller for bread $(3.5 \mathrm{~g})$ than potatoes $(6.5 \mathrm{~g})$. This was expected, as number of chewing cycles, chewing forces and jaw movements are closely linked to the structural properties of food. ${ }^{17,34,35}$ We use the peak force as a mean to distinguish firmness of the samples, which are shown in Fig. 2 for the different stages of oral consumption. Based on the bolus peak force, bread boli are firmer than potatoes at all stages of consumption. For example, bolus peak force at $33 \%$ of total mastication time was $0.47 \pm 0.04 \mathrm{~N}$ for bread and $0.20 \pm 0.02 \mathrm{~N}$ for potato, while at $100 \%$ or mastication, bread showed a peak force of $0.27 \pm 0.02 \mathrm{~N}$ and potato showed a peak force of $0.13 \pm 0.01 \mathrm{~N}$ (see Fig. 2). Bread therefore requires more physiological effort at all stages of consumption.
(A)
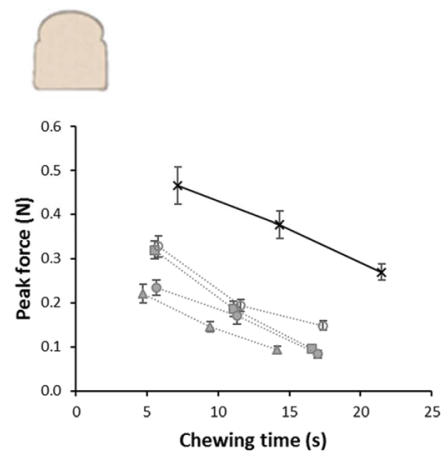

(C)

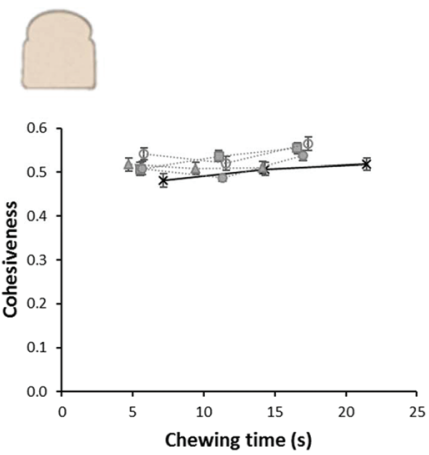

(B)
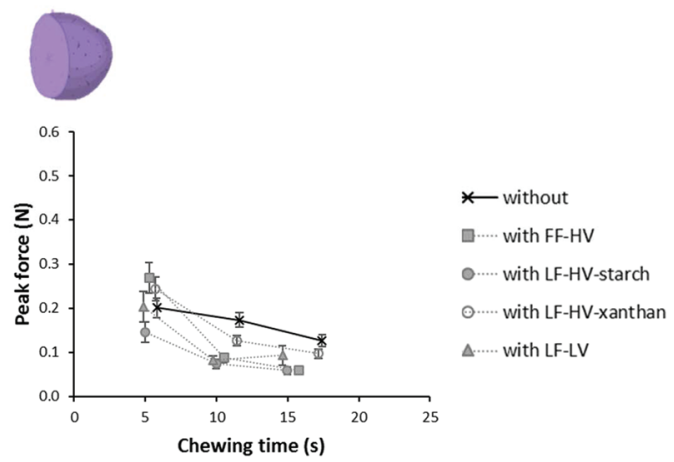

(D)
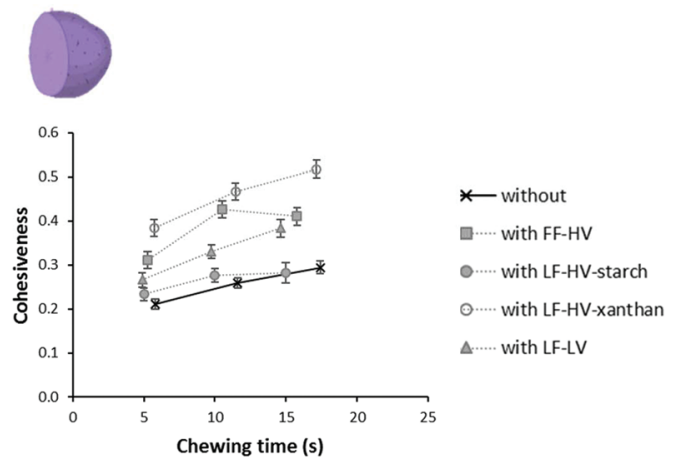

Fig. 2 Bolus mechanical properties (peak force, cohesiveness) throughout mastication for bread (A, C) and cooked potato (B, D) without and with different mayonnaises. Peak force refers to bolus firmness, cohesiveness refers to the degree to which food sticks together. Error bars represent standard error of the mean. The abbreviations are explained in Table 1. Lines are added to guide the eye. 
The effect of condiment addition on oral processing behavior depended on the type of carrier food. On average, the addition of mayonnaises decreased the number of chews from $23 \pm 2$ to $16 \pm 2$ for bread $(-30 \%)$ and from $20 \pm 1$ to $17 \pm 1$ for potato $(-15 \%)$, showing that condiments facilitated mastication of bread to a larger extent than that of cooked potato (both absolutely and by percentage). Hence, condiments may aid bolus formation of dry carrier foods more than carriers with a high moisture content (moisture content: $44 \pm 3$ wt $\%$ for bread and $88 \pm 1 \mathrm{wt} \%$ for potato). In the case of low water content carriers, water might be absorbed faster and thus mixed more easily with the carrier, whereas in high moisture content carriers water might be absorbed slower and mixing might occur mostly due to mechanical forces. In view of these findings, it should be noted that mayonnaise was mixed with bread in a $1: 1$ weight ratio, whereas potato was mixed with mayonnaise in a 2:1 weight ratio. Thus, a relatively higher amount of mayonnaise was present in bread-mayonnaise combinations than in the potato-mayonnaise combinations. This may also contribute to the larger effect for bread. We can therefore not draw firm conclusions on the effect of absorption or speed of mixing on oral processing behavior. The reason why different ratios were chosen was that these weight ratios are naturally applied by consumers when preparing these composite foods and hence provide a more realistic context for consumer consumption. ${ }^{12,13}$ The larger amount of condiment may therefore also be responsible for the faster moistening. Thus, when considering naturally applied condiment: carrier weight ratios, condiments may assist bolus formation of relatively dry foods such as bread more than carrier foods with a high moisture content such as cooked potatoes due to two reasons: (1) faster moisture absorption and/or (2) the presence of more moisture due to more condiment.

3.1.3. Effect of condiment properties on oral processing behavior of composite foods. When comparing mayonnaises differing in fat content (FF-HV versus LF-HV-starch), no significant differences in oral processing behavior were observed (Table 3A). Hence, as oral processing behavior (i.e. number of chews, chewing time, eating rate per bite) is not affected by fat content, replacing a full-fat condiment by a low-fat alternative ( 2743 vs. $1125 \mathrm{~kJ}$ per $100 \mathrm{~mL}$ ) can lower energy intake without affecting oral processing behavior.

When comparing mayonnaises differing in viscosity (LF-HV-starch versus LF-LV), composite foods with low viscosity mayonnaise were swallowed after slightly shorter chewing time than those with high viscosity mayonnaise $(10 \pm 1 \mathrm{~s}$ compared to $9 \pm 1 \mathrm{~s}$ for bread and $11 \pm 1 \mathrm{~s}$ compared to $10 \pm 1 \mathrm{~s}$ for potato, $p=0.033)$. This is likely due to the faster migration of low viscosity mayonnaise into and throughout the bread bolus compared to the migration of the high viscosity mayonnaise, leading to faster moistening of the bolus. In the case of potato, the shorter chewing time is not explained by faster moisture migration, as moisture content of potato is already high. The difference in chewing time is likely more related to the fact that mayonnaise is used to adhere the different potato pieces together in a bolus. This mixing step is easier for low viscosity mayonnaise then for a high viscosity one. Although these differences in chewing time seem relatively small (approximately 1 second per bite), we have to consider that carrier-condiment combinations are not eaten as a single bite but as part of a meal. Consequently, over the consumption of multiple bites, adding condiments with a lower viscosity results in a higher eating rate (from $46 \pm 3$ to $55 \pm 4 \mathrm{~g} \mathrm{~min}^{-1}$ for bread and from $61 \pm 3$ to $70 \pm 4 \mathrm{~g} \mathrm{~min}^{-1}$ for potato; Fig. 1) compared to that of condiments with high viscosity. Addition of low viscosity condiments might therefore lead to higher food intake.

\subsection{Effect of condiments on bolus properties and sensory perception of carrier foods}

3.2.1. Bread versus potato: effect of condiment addition on bolus formation and sensory perception. Addition of mayonnaises changes the bolus properties and sensory perception of bread and cooked potato (Table $3 \mathrm{~B}$ and C). Throughout consumption, mayonnaises were mixed with carrier foods leading to structural changes. Illustrative pictures of expectorated boli are shown in Table 4. As already discussed, the addition of mayonnaise led to a decrease in peak force for the bread bolus (Fig. 2A), while it remained rather constant for the potato bolus (Fig. 2B). With respect to cohesiveness, we see that this did not change for the bread boli (Fig. 2C) but increased for potato boli (Fig. 2D). The pictures also show that part of the mayonnaise was present on the outer surface of the bolus throughout the entire process of mastication, by which it could contribute to the lubrication of the bolus, next to lubrication by saliva. Indeed, with the presence of mayonnaise, the coefficient of friction decreased (Fig. 3), indicating increased lubrication, and less saliva incorporation was required before swallowing (Fig. 4). These results again indicate that condiments assist saliva in bolus formation in a slightly different way for bread and potato. As explained before, this is most likely due to the water absorption capability of these products. In the case of bread, saliva/mayonnaise migrates into the bread, where it moistens and softens helping to form a compact moistened bolus without falling apart into pieces. In the case of potato, no direct saliva incorporation is obtained as potato already contains a high water content. Instead, the potato is first broken down in multiple pieces. Saliva and additional moisture or fat are then used to adhere bolus pieces to form a safe-to-swallow bolus. For bread and potato, saliva facilitates bolus formation but by different mechanisms, i.e. bolus moistening or bolus adherence. Regardless of the mechanism, bolus properties for safe swallowing were reached after shorter chewing times with the addition of mayonnaise for both foods. It appears that when moisture is used for adherence or for moistening, low viscosity condiments are beneficial, as they can easily spread between potato boli fragments and also migrate easier into bread. Consequently, due to moisture incorporation, trained subjects perceived carriers with mayonnaises as smoother (from $0.7 \pm 0.3$ to $2.2 \pm 0.2$ for bread, from $0.1 \pm 0.1$ to $1.1 \pm 0.2$ for potato), less dry (from 6.8 \pm 0.6 to $3.5 \pm 0.1$ for bread, from $7.7 \pm 0.3$ to $5.1 \pm 0.2$ for potato), less firm (from $5.6 \pm 0.5$ to $4.4 \pm 0.1$ ), and the fibrous 
Table 4 Representative pictures of expectorated boli at three time points throughout mastication (33, 66 and $100 \%$ of total mastication time) for bread (left) and cooked potato (right) without and with different mayonnaises. Chewing times before expectoration (s), moisture content (wt\%), saliva content ( $\mathrm{g}$ per $\mathrm{g}$ dry weight) and fat content (wt\%) are reported for each sample and time point (mean \pm standard error of the mean)

\begin{tabular}{|c|c|c|c|c|c|c|}
\hline \multirow[b]{2}{*}{ Sample } & \multicolumn{3}{|c|}{ Bread boli } & \multicolumn{3}{|c|}{ Potato boli } \\
\hline & $33 \%$ & $66 \%$ & $100 \%$ & $33 \%$ & $66 \%$ & $100 \%$ \\
\hline \multicolumn{7}{|l|}{ Without } \\
\hline Chewing time & 7 & 14 & 21 & 6 & 12 & 17 \\
\hline Moisture content & $54 \pm 1$ & $57 \pm 1$ & $60 \pm 2$ & $82 \pm 0$ & $83 \pm 0$ & $83 \pm 0$ \\
\hline Saliva content & $0.4 \pm 0.0$ & $0.6 \pm 0.1$ & $0.9 \pm 0.1$ & $1.3 \pm 0.1$ & $1.7 \pm 0.1$ & $1.5 \pm 0.2$ \\
\hline Fat content & - & - & - & - & - & - \\
\hline \multicolumn{7}{|l|}{ FF-HV } \\
\hline Chewing time (s) & 6 & 11 & 17 & 5 & 11 & 16 \\
\hline Moisture content (\%) & $42 \pm 1$ & $45 \pm 1$ & $48 \pm 1$ & $65 \pm 1$ & $66 \pm 1$ & $66 \pm 1$ \\
\hline Saliva content $(\ldots)$ & $0.4 \pm 0.0$ & $0.4 \pm 0.0$ & $0.4 \pm 0.0$ & $0.6 \pm 0.0$ & $0.7 \pm 0.0$ & $0.7 \pm 0.0$ \\
\hline Fat content $(\%)$ & - & - & $54 \pm 1$ & - & - & $60 \pm 1$ \\
\hline \multicolumn{7}{|l|}{ LF-HV-starch } \\
\hline Chewing time (s) & 6 & 11 & 17 & 5 & 10 & 15 \\
\hline Moisture content (\%) & $63 \pm 1$ & $64 \pm 1$ & $67 \pm 1$ & $77 \pm 1$ & $79 \pm 0$ & $80 \pm 0$ \\
\hline Saliva content $(\ldots)$ & $0.3 \pm 0.1$ & $0.5 \pm 0.1$ & $0.7 \pm 0.1$ & $0.8 \pm 0.1$ & $1.0 \pm 0.1$ & $1.2 \pm 0.1$ \\
\hline Fat content $(\%)$ & - & - & $25 \pm 1$ & - & - & $27 \pm 1$ \\
\hline \multicolumn{7}{|l|}{ LF-HV-xanthan } \\
\hline Chewing time (s) & 6 & 12 & 17 & 6 & 11 & 17 \\
\hline Moisture content (\%) & $62 \pm 0$ & $65 \pm 1$ & $66 \pm 1$ & $79 \pm 0$ & $79 \pm 1$ & $80 \pm 0$ \\
\hline Saliva content $(. .)$. & $0.2 \pm 0.0$ & $0.4 \pm 0.1$ & $0.5 \pm 0.0$ & $0.6 \pm 0.1$ & $0.9 \pm 0.1$ & $1.0 \pm 0.1$ \\
\hline Fat content $(\%)$ & - & - & $19 \pm 1$ & - & - & $23 \pm 1$ \\
\hline \multicolumn{7}{|l|}{ LF-LV } \\
\hline Chewing time (s) & 5 & 9 & 14 & 5 & 10 & 15 \\
\hline Moisture content (\%) & $62 \pm 1$ & $65 \pm 1$ & $67 \pm 0$ & $79 \pm 1$ & $80 \pm 0$ & $80 \pm 0$ \\
\hline Saliva content $(\ldots)$ & $0.2 \pm 0.0$ & $0.4 \pm 0.1$ & $0.6 \pm 0.0$ & $0.7 \pm 0.1$ & $0.9 \pm 0.1$ & $1.0 \pm 0.1$ \\
\hline Fat content $(\%)$ & - & - & $28 \pm 1$ & - & - & $29 \pm 1$ \\
\hline
\end{tabular}

(A)

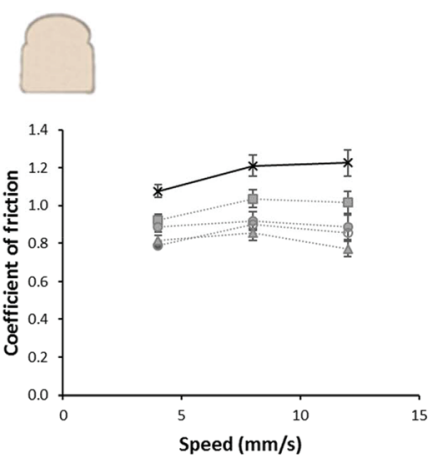

(B)

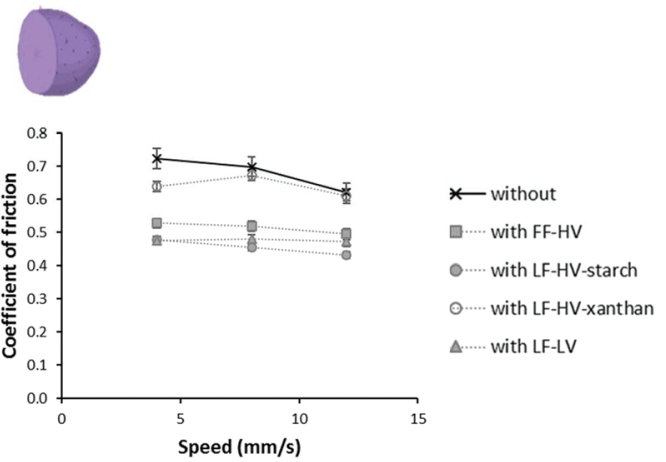

Fig. 3 Bolus friction coefficient at the moment of swallowing as a function of speed for bread (A) and cooked potato (B) without and with different mayonnaises. Error bars represent standard error of the mean. The abbreviations are explained in Table 1. Lines are added to guide the eye. 
(A)

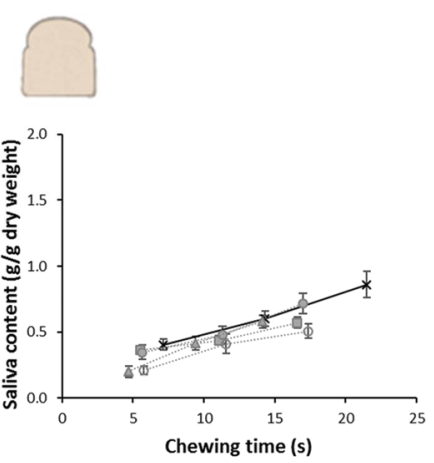

(B)

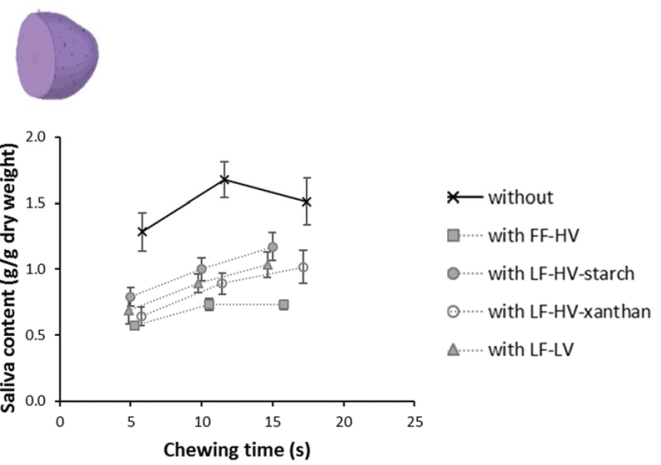

Fig. 4 Bolus saliva content at the moment of swallowing for bread (A) and cooked potato (B) without and with different mayonnaises. Error bars represent standard error of the mean. The abbreviations are explained in Table 1. Lines are added to guide the eye.

structure of bread was perceived to a lesser extent (from $10.6 \pm$ 0.7 to $8.4 \pm 0.2$ ). In addition, the presence of individual potato pieces was perceived to a lesser extent (from $11.4 \pm 0.4$ to $9.0 \pm$ 0.2 ), indicating increased cohesiveness perception. Hence, the measured bolus properties were in line with the perceived sensory characteristics.

3.2.2. Effect of condiment properties on bolus properties and sensory perception of composite foods. When comparing. mayonnaises differing in fat content (i.e. FF-HV versus LF-HVstarch), bolus composition distinctly differed in moisture and fat content. As expected, boli with FF-HV mayonnaise were higher in fat, whereas boli with LF-HV-starch mayonnaise were higher in moisture content (Table 3B and 4). As no differences in chewing behavior were observed between full-fat and low-fat mayonnaise for either food (Fig. 1), fat and moisture seem to facilitate bolus formation of these carriers to a similar extent. This may be expected for bread as migration of the mayonnaise is driven by viscosity, which is the same for both mayonnaises. Larger differences may have been expected for potato. As the mayonnaise is used as a "glue" to adhere particles together, the fat content could have had a beneficial effect. However, it seems that composition of the mayonnaise does not change the affinity towards the potato to a large enough extent to change adherence. Adherence also seems to be determined by viscosity rather than by composition. With respect to sensory perception, assessed by a trained sensory panel, few differences were observed as only 2 out of 20 sensory attributes were significantly influenced by mayonnaise fat content (Table 3C). Only the attribute "fatty" (during consumption and after swallowing) was significantly different.

The previous results on chewing behavior (Fig. 1, section 3.1.3) indicate that mayonnaise viscosity seems to be more important in bolus formation than fat content. When comparing mayonnaises differing in viscosity (i.e. LF-HV-starch versus LF-LV), some changes in bolus properties throughout mastication were found. For bread, bolus peak force was lower for low viscosity mayonnaise than high viscosity mayonnaise (Fig. 2A) at $33 \%$ of total mastication time. Low viscosity mayonnaise is able to penetrate into the bread bolus faster than high viscosity mayonnaise, as low viscosity liquids have a higher migration rate and are more prone to capillary action by the small pores in the bread structure. ${ }^{36}$ This leads to faster penetration, reducing the coefficient of friction (Fig. 3A) and time to form a safe-to-swallow bolus. This was evidently perceivable by the trained sensory panel, as bread carriers with low viscosity mayonnaises were rated significantly less firm $(3.5 \pm 0.3$ compared to $4.8 \pm 0.2)$ and more absorbing $(7.3 \pm 0.5$ compared to $5.0 \pm 0.4)$ than those with high viscosity mayonnaise. For potatoes, bolus cohesiveness increased to a larger extent at an earlier stage of consumption for the low viscosity mayonnaise compared to high viscosity mayonnaise (Fig. 2D). This indicates again that low viscosity mayonnaise mixed more easily with the potato pieces to form a cohesive and safe-toswallow bolus after less time. Thus, viscosity is likely the driving force of fast adherence of particles and bolus formation. As no differences between firmness were observed (Fig. 2B), swallowing of potato-condiment combinations may be more related to cohesiveness than bolus firmness. This is in line with our assumption that mayonnaise helps bolus particles to adhere together.

Regarding sensory perception, as assessed by a trained sensory panel, it is important to mention that sensory evaluations were largely impacted by mayonnaise viscosity (Table 3C). Sensory perception therefore seems to be dominated by viscosity more than fat content. For bread, 7 out of 20 attributes were significantly different for LF-HV-starch and LF-LV mayonnaise while 5 out of 20 attributes were significantly different for potatoes. In particular, carrier-mayonnaise combinations were perceived as significantly less creamy, fatty and velvety when low viscosity mayonnaise was added. These are desired mouthfeel attributes that contribute to food appreciation. ${ }^{37,38}$ Thus, in case of mayonnaise, decreasing viscosity probably leads to a lower food liking.

3.2.3. Role of lubrication in swallowing and sensory perception of composite foods. Lubrication behavior of foods has been suggested to influence both ease of swallowing and 
smoothness perception. ${ }^{39-41}$ Fig. 3 shows the friction coefficients for the composite boli mixed with different mayonnaises. These results show that lower friction coefficients are obtained for composite foods with added mayonnaise compared to the carriers without mayonnaise. Thus, in addition to faster migration and mixing, mayonnaises can also aid bolus formation and swallowing by increasing lubrication (lower friction). We also examined whether lubrication behavior was linked to specific sensory attributes. The coefficient of friction was correlated to perceived smoothness $(r=-0.82$ for bread, $r=-0.85$ for potato), perceived creaminess $(r=-0.62$ for bread, $r=-0.62$ for potato) and dry, rough after-feel perception ( $r=0.91$ for bread, $r=0.92$ for potato).

To better understand how condiments affect oral processing behavior and smoothness perception of composite foods, we also sought to gain information on the lubrication ability of the ingredients present in the food boli (i.e. the role of fat content and viscosity). Although condiment properties tend to impact lubrication behavior of bread-mayonnaise combinations (Fig. 3A), this effect is not clearly observed in potatomayonnaise combinations (Fig. 3B). It is not yet clear how fat and moisture are distributed throughout the bolus and how that may influence lubrication. In addition, for similar moist- ure content, particle sizes of boli fragments has been shown to influence lubrication. ${ }^{31}$ We hypothesize that dry foods, such as bread, soften via moisture uptake by which lubrication is more effectively facilitated than by adding fat. In the case of potato, either water or fat is used to keep the particles together without a softening effect. Therefore, we observed a reduced effect of condiment properties on lubrication for potato.

To visualize the relation of the different aspects on oral processing behavior, we have summarized the results in MFA individuals map (Fig. 5). The fat content of condiments did not have a large impact on oral processing behavior, bolus properties or sensory characteristics of carrier-condiment combinations as the FF-HV and LF-HV-starch are positioned close to each other. Changing the viscosity of condiments, on the other hand, had a larger effect on both the oral processing behavior and sensory perception of the carrier-condiment combinations as LF-HV-starch and LF-LV mayonnaises are positioned further apart. Carriers with low viscosity mayonnaise were processed using fewer chews for a shorter time, resulting in faster bread softening and faster potato adherence. Additionally, when assessed by a trained sensory panel, they were perceived as less creamy, fatty and velvety than the high viscosity mayonnaise combinations.

\section{(A) Bread with mayonnaises}
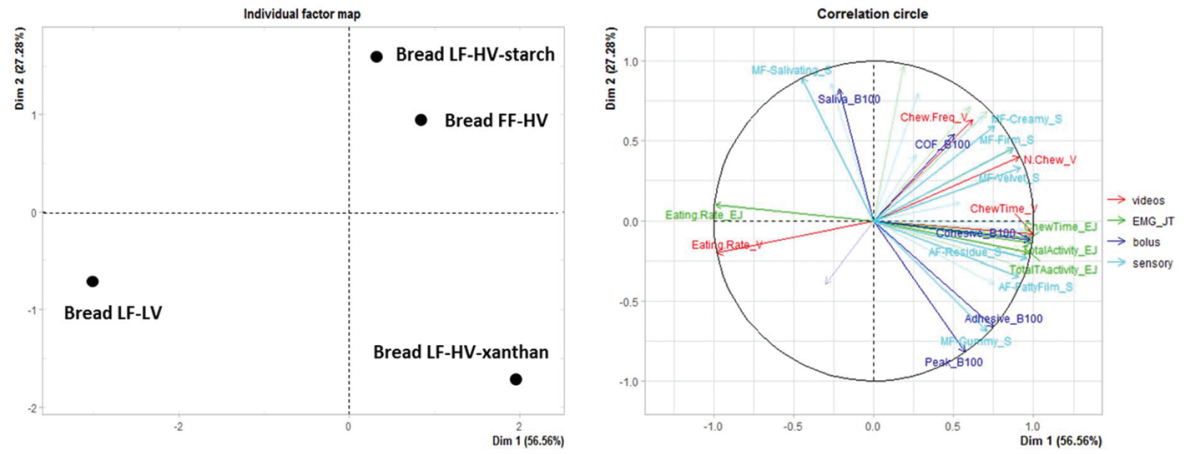

(B) Potato with mayonnaises
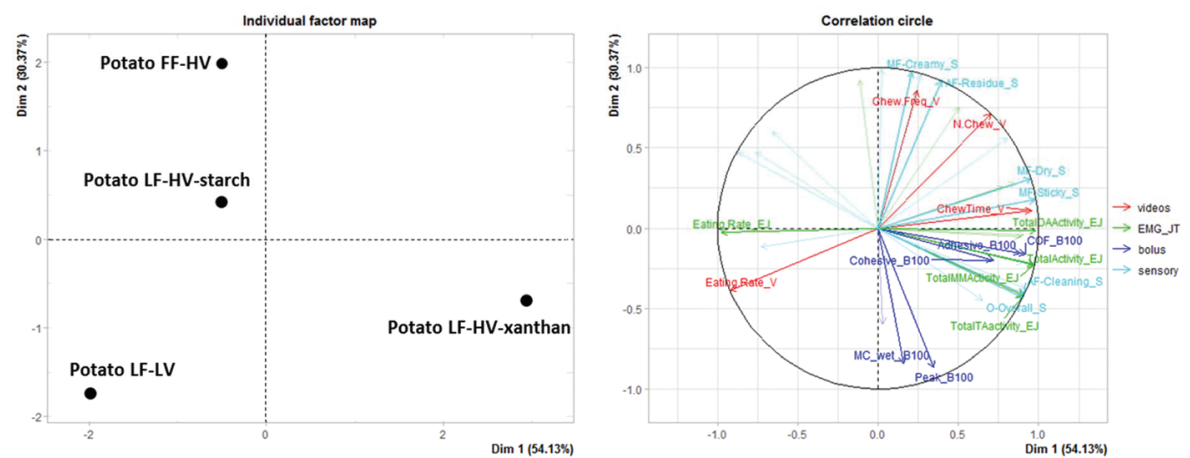

Fig. 5 Multiple Factor Analysis (MFA) on the four different datasets (video recordings, EMG and jaw tracking, bolus properties at the moment of swallowing, and sensory characteristics) for bread with different mayonnaises (A) and cooked potato with different mayonnaises (B). Only those parameters with a significant mayonnaise effect during mixed models were considered (37 parameters; see Table 3). The individuals map (samples) is shown on the left, and the variables map (parameters) is shown on the right. Different colors indicate different datasets, and only the 20 variables with the highest contribution are displayed in words. The abbreviations are explained in Table 1. 


\subsection{Practical implications}

Our results for breads and potato showed that addition of any mayonnaise to carrier foods contributed to faster eating rates by providing bolus softening (bread), adherence of bolus pieces (potato) and/or lubrication (bread, potato). Faster eating rate can lead to higher energy food intake, ${ }^{42-44}$ especially for composite foods containing condiments high in fat and energy. Higher food intake may not be beneficial from a health perspective. Nevertheless, providing condiments to a meal might also promote healthy eating. For instance, adding small amounts of condiments to vegetables or whole grain staple foods (that are generally less liked due to their flavor or texture) might increase food intake, allowing recommended daily intakes of specific nutrients to be reached. In addition, when targeting the elderly population at risk of malnutrition due to impaired oral processing abilities, ${ }^{45,46}$ addition of condiments to solid foods may assist in bolus formation and easier chewing, consequently, contribute to a desired increase in food intake.

Modest nuances in energy intake of composite foods could be achieved by changing specific condiment properties. Fat content is inherently related a high energy density of foods, and full fat condiments increase both fat and calorie intake, which is usually undesirable. The present study highlights that changing the fat content of condiments did not affect chewing behavior and only modestly affected sensory perception of composite foods. This implies that replacing full-fat condiments with low-fat options with a comparable viscosity could be a promising strategy to reduce fat and, ultimately, energy intake among the general population in a relatively unconscious way. In addition to changing the fat content, also the viscosity can be used to change food intake. Changing the viscosity of condiments influences eating rate and is also likely to affect food appreciation. Low viscosity condiments can increase eating rate, while high viscosity condiments reduce eating rate. Modification of eating rate is emerging as a key parameter to impact energy intake in unrestrained consumers. ${ }^{47}$ Therefore, such changes may be used to target energy intake behavior of different consumer groups. For example, increasing viscosity with less fat could be used to decrease total food and energy intake by increasing eating rate. Similarly, adding low viscosity condiments to foods may increase food intake, which can be used to increase uptake of vegetables by children or increase total food intake by the elderly.

We must note that these results have been obtained for bread and potato only, and should be confirmed for other categories of carrier foods. However, as we see the same effects in two different food categories (dry foods and foods with higher moisture content), we speculate that these effects can be generalized to a large variety of foods. It would be interesting to see how condiments influence oral processing behavior, bolus formation and sensory properties of foods that are more sticky or more brittle. In addition, the effects should also be further confirmed by a consumer panel to confirm generalizability towards the general consumer population.

\section{Conclusions}

Consumers frequently combine foods that vary greatly in composition, structure and energy density. The aim of this study was to understand the role of condiments, themselves varying in composition or rheological properties, in bolus formation facilitation and how they influence oral processing behavior and sensory perception of solid carrier foods. This study shows that addition of condiments facilitates bolus formation of solid carrier foods, regardless of specific condiment properties. All condiments assisted saliva in bolus formation by increasing lubrication (lower coefficient of friction, less saliva incorporation) and impacting the degree of bolus structure (decreased firmness of bread bolus, increased cohesiveness of potato bolus) allowing the bolus to be safely swallowed after fewer chews and shorter chewing times. Our results highlight that, although number of chews and chewing time decreased considerably with the addition of condiments, subjects did not adapt their muscle activities nor jaw movements per chew.

We conclude that oral processing behavior of carrier-condiment combinations is mainly affected by the presence of condiments and, to a smaller extent, the specific properties of the condiment. When comparing the influence of different condiment properties (fat content, viscosity), only small effects on chewing behavior were observed. For bolus formation, larger effects of condiment properties were seen. Viscosity played an important role in bolus formation for two different reasons: (1) water absorption of dry foods softens the bolus, and (2) moisture assists in adhering separate particles into a bolus. Both mayonnaise fat content and viscosity influenced sensory perception of composite foods considerably.

This is the first study that shows the potential of systematically modifying single food properties to influence oral processing behavior and sensory perception of composite foods. These results suggest that tailoring carrier-condiment combinations might largely alter food intake, which could be an effective strategy for modulating food intake in different consumer groups. Further studies with consumers are required to investigate whether such single food modifications affect food intake sustainably throughout an entire meal and after multiple exposures.

\section{Conflicts of interest}

There are no conflicts to declare.

\section{Acknowledgements}

The authors would like to thank Paulina Skrzeszewska for her help with the mayonnaise preparations, Sophie Caulier, Desiree Ronckers and Robin van Schaik for their contribution to the video and bolus sessions, Steef Klepke and Rutger Brouwer for their contribution to the sensory evaluation ses- 
sions, and Philipp Fuhrmann for sharing his expertise with respect to the tribology methodology.

The project is funded by TiFN, a public-private partnership on precompetitive research in food and nutrition. The public partners are responsible for the study design, data collection and analysis, decision to publish, and preparation of the manuscript. The private partners have contributed to the project through regular discussion. The private partners are Royal Friesland Campina, Fromageries Bel and Unilever. This research was performed with additional funding from the Top Consortia for Knowledge and Innovation of the Dutch Ministry of Economic Affairs.

\section{References}

1 C. Spence, The psychology of condiments: A review, Int. J. Gastron. Food Sci., 2018, 11, 41-48.

2 C. Van Rossum, E. Buurma-Rethans, F. Vennemann, M. Beukers, H. A. Brants, E. De Boer and M. C. Ocké, The diet of the Dutch: Results of the first two years of the Dutch National Food Consumption Survey 2012-2016, RIVM letter report 2016-0082, 2016.

3 M. T. Paulsen, T. Ueland, A. N. Nilsen, Å. Öström and M. Hersleth, Sensory perception of salmon and culinary sauces - An interdisciplinary approach, Food Qual. Prefer., 2012, 23, 99-109.

4 M. Santagiuliana, M. Christaki, B. Piqueras-Fiszman, E. Scholten and M. Stieger, Effect of mechanical contrast on sensory perception of heterogeneous liquid and semisolid foods, Food Hydrocolloids, 2018, 83, 202-212.

5 M. Santagiuliana, B. Piqueras-Fiszman, E. van der Linden, M. Stieger and E. Scholten, Mechanical properties affect detectability of perceived texture contrast in heterogeneous food gels, Food Hydrocolloids, 2018, 80, 254-263.

6 J. Tang, D. S. Larsen, L. Ferguson and B. J. James, Textural complexity model foods assessed with instrumental and sensory measurements, J. Texture Stud., 2017, 48, 9-22.

7 R. J. Hyde and S. A. Witherly, Dynamic contrast: A sensory contribution to palatability, Appetite, 1993, 21, 1-16.

8 N. A. Miele, R. Di Monaco, S. Cavella and P. Masi, Effect of meal accompaniments on the acceptability of a walnut oilenriched mayonnaise with and without a health claim, Food Qual. Prefer., 2010, 21, 470-477.

9 A. S. Szczesniak and E. L. Kahn, Texture contrasts and combinations: A valued consumer attribute, J. Texture Stud., 1984, 15, 285-301.

10 L. Engelen, A. Fontijn-Tekamp and A. Van Der Bilt, The influence of product and oral characteristics on swallowing, Arch. Oral Biol., 2005, 50, 739-746.

11 M. B. D. Gavião, L. Engelen and A. Van Der Bilt, Chewing behavior and salivary secretion, Eur. J. Oral Sci., 2004, 112, 19-24.

12 A. van Eck, N. Hardeman, N. Karatza, V. Fogliano, E. Scholten and M. Stieger, Oral processing behavior and dynamic sensory perception of composite foods: Toppings assist saliva in bolus formation, Food Qual. Prefer., 2019, 71, 497-509.

13 A. van Eck, C. Wijne, V. Fogliano, M. Stieger and E. Scholten, Shape up! How shape, size and addition of condiments influence eating behavior towards vegetables, Food Funct., 2019, 10, 5739-5751.

14 J. Chen, Food oral processing: Some important underpinning principles of eating and sensory perception, Food Struct., 2014, 1, 91-105.

15 M. Devezeaux de Lavergne, F. van de Velde and M. Stieger, Bolus matters: the influence of food oral breakdown on dynamic texture perception, Food Funct., 2017, 8, 464-480.

16 E. A. Foegeding, M. Stieger and F. van de Velde, Moving from molecules, to structure, to texture perception, Food Hydrocolloids, 2017, 68, 31-42.

17 E. Çakir, C. J. Vinyard, G. Essick, C. R. Daubert, M. Drake and E. A. Foegeding, Interrelations among physical characteristics, sensory perception and oral processing of proteinbased soft-solid structures, Food Hydrocolloids, 2012, 29, 234-245.

18 M. Devezeaux de Lavergne, V. M. G. Strijbosch, A. W. M. Van den Broek, F. Van de Velde and M. Stieger, Uncoupling the impact of fracture properties and composition on sensory perception of emulsion-filled gels, J. Texture Stud., 2016, 47, 92-111.

19 M. Devezeaux de Lavergne, F. van de Velde, M. A. J. S. van Boekel and M. Stieger, Dynamic texture perception and oral processing of semi-solid food gels: Part 2: Impact of breakdown behaviour on bolus properties and dynamic texture perception, Food Hydrocolloids, 2015, 49, 61-72.

20 H. Koc, C. J. Vinyard, G. K. Essick and E. A. Foegeding, Food oral processing: Conversion of food structure to textural perception, Annu. Rev. Food Sci. Technol., 2013, 4, 237266.

21 E. M. Krop, M. M. Hetherington, M. Holmes, S. Miquel and A. Sarkar, On relating rheology and oral tribology to sensory properties in hydrogels, Food Hydrocolloids, 2019, 88, 101-113.

22 M. Devezeaux de Lavergne, J. A. M. Derks, E. C. Ketel, R. A. de Wijk and M. Stieger, Eating behaviour explains differences between individuals in dynamic texture perception of sausages, Food Qual. Prefer., 2015, 41, 189-200.

23 L. Mioche, P. Bourdiol and S. Monier, Chewing behaviour and bolus formation during mastication of meat with different textures, Arch. Oral Biol., 2003, 48, 193-200.

24 C. Yven, J. Culioli and L. Mioche, Meat bolus properties in relation with meat texture and chewing context, Meat Sci., 2005, 70, 365-371.

25 J. Gao, J. J.-X. Ong, J. Henry and W. Zhou, Physical breakdown of bread and its impact on texture perception: A dynamic perspective, Food Qual. Prefer., 2017, 60, 96-104.

26 S. Jourdren, A. Saint-Eve, M. Panouillé, P. Lejeune, I. Déléris and I. Souchon, Respective impact of bread structure and oral processing on dynamic texture perceptions through statistical multiblock analysis, Food Res. Int., 2016, 87, 142-151. 
27 M. Panouillé, A. Saint-Eve, I. Déléris, F. Le Bleis and I. Souchon, Oral processing and bolus properties drive the dynamics of salty and texture perceptions of bread, Food Res. Int., 2014, 62, 238-246.

28 A. K. Young, J. N. Cheong, K. D. Foster, D. I. Hedderley, M. P. Morgenstern and B. J. James, Exploring the links between texture perception and bolus properties throughout oral processing. Part 1: Breakdown paths, J. Texture Stud., 2016, 47(6), 461-473.

29 W. L. Hylander and K. R. Johnson, Modelling relative masseter force from surface electromyograms during mastication in non-human primates, Arch. Oral Biol., 1993, 38, 233-240.

30 C. J. Vinyard, C. E. Wall, S. H. Williams and W. L. Hylander, Patterns of variation across primates in jaw-muscle electromyography during mastication, Am. Zool., 2008, 48, 294-311.

31 P. L. Fuhrmann, M. Aguayo-Mendoza, B. Jansen, M. Stieger and E. Scholten, Characterisation of friction behaviour of intact soft solid foods and food boli, Food Hydrocolloids, 2020, 100, 105441.

32 A. Kuznetsova, P. B. Brockhoff and R. H. B. Christensen, ImerTest: Tests in Linear Mixed Effects Models, 2016.

33 S. Lê, J. Josse and F. Husson, FactoMineR: An R Package for Multivariate Analysis, 2008.

34 S. Ishihara, M. Nakauma, T. Funami, T. Tanaka, K. Nishinari and K. Kohyama, Electromyography during oral processing in relation to mechanical and sensory properties of soft gels, J. Texture Stud., 2011, 42, 254-267.

35 K. Kohyama, Z. Gao, T. Watanabe, S. Ishihara, S. Nakao and T. Funami, Relationships Between Mechanical Properties Obtained from Compression Test and Electromyography Variables During Natural Oral Processing of Gellan Gum Gels, J. Texture Stud., 2017, 48, 66-75.

36 Z. Hicsasmaz and J. T. Clayton, Mechanisms involved in the infusion of starch based porous food materials by oil based liquid foods, J. Food Process Eng., 1995, 18, 267-286.
37 G. Ares, A. Giménez, C. Barreiro and A. Gámbaro, Use of an open-ended question to identify drivers of liking of milk desserts. Comparison with preference mapping techniques, Food Qual. Prefer., 2010, 21, 286-294.

38 N. J. Richardson-Harman, R. Stevens, S. Walker, J. Gamble, M. Miller, M. Wong and A. McPherson, Mapping consumer perceptions of creaminess and liking for liquid dairy products, Food Qual. Prefer., 2000, 11, 239-246.

39 C. L. Campbell, E. A. Foegeding and F. van de Velde, A Comparison of the lubrication behavior of whey protein model foods using tribology in linear and elliptical movement, J. Texture Stud., 2017, 48(4), 335-341.

40 A. Sarkar and E. M. Krop, Marrying oral tribology to sensory perception: a systematic review, Curr. Opin. Food Sci., 2019, 27, 64-73.

41 J. R. Stokes, M. W. Boehm and S. K. Baier, Oral processing, texture and mouthfeel: From rheology to tribology and beyond, Curr. Opin. Colloid Interface Sci., 2013, 18, 349-359.

42 C. de Graaf and F. J. Kok, Slow food, fast food and the control of food intake, Nat. Rev. Endocrinol., 2010, 6, 290293.

43 K. McCrickerd and C. Forde, Consistency of eating rate, oral processing behaviours and energy intake across meals, Nutrients, 2017, 9, 891.

44 E. Robinson, E. Almiron-Roig, F. Rutters, C. de Graaf, C. G. Forde, C. Tudur Smith, S. J. Nolan and S. A. Jebb, A systematic review and meta-analysis examining the effect of eating rate on energy intake and hunger, Am. J. Clin. Nutr., 2014, 100, 123-151.

45 M. Hickson, Malnutrition and ageing, Postgrad. Med. J., 2006, 82, 2-8.

46 L. Pauly, P. Stehle and D. Volkert, Nutritional situation of elderly nursing home residents, Z. Gerontol. Geriatr., 2007, 40, 3-12.

47 C. G. Forde, M. Mars and K. De Graaf, Ultra-Processing or Oral Processing? A Role for Energy Density and Eating Rate in Moderating Energy Intake from Processed Foods, Curr. Dev. Nutr., 2020, 4, nzaa019. 